\title{
What might the environmental policy of Tokyo Metropolitan Government achieve?
}

\author{
Masaaki Hosomi
}

Published online: 20 October 2010

(C) Springer-Verlag 2010

The summer was infernally hot this year in Japan. Many observation sites recorded highest temperatures since 1875 . Official weather terms like "Nettaiya" (a sultry night when temperature does not drop below $25^{\circ} \mathrm{C}$ ) and "Moushobi" (a day when temperature goes over $35^{\circ} \mathrm{C}$ ) were reported on television and newspapers every day. Japan seems to have become a tropical country. If this is the harbinger of global warming, which needs to be prevented per Kyoto Protocol, adaptation seems to be of higher priority now than mitigation.

The Kyoto Protocol, which set the numerical targets for greenhouse gas (GHG) emissions of developed countries, established the target period from 2008 to 2012. The GHG reduction target for Japan was $6 \%$ in 2010 compared to the benchmark year of 1990 . However, the total GHG emission in 2008 was 1.282 billion ton according to the Ministry of the Environment. This total emission was higher by $1.6 \%$ than that in the benchmark year due to increased consumption of fossil fuels in the commercial/business and household sectors. Comparing this total emission with the counterpart in 2007, the amount in 2008 was reduced by $6.4 \%$ due to decreased fossil fuel use in the industrial sector. This decrease was congruent with the worldwide recession due to the financial crisis of 2008 leading to a decrease in energy demand in various sectors, especially industry.

Various actions toward GHG emission reduction have been taken at the national level in Japan. In accordance with the Kyoto Protocol of the 1998 Conference of the Parties Third Framework Convention on Climate Change

M. Hosomi $(\bowtie)$

Department of Chemical Engineering, Tokyo University

of Agriculture and Technology, Tokyo, Japan

e-mail: hosomi@cc.tuat.ac.jp
(COP3), Japan adopted, as the first step, promotion of measures through various public and private entities to cope with global warming. In 2008, the law was revised to achieve a numerical reduction target of $6 \%$ by the Kyoto Protocol. The main point of the revision was to achieve accurate estimation, reporting, and publicity of GHG reduction. The revision ordered companies (units of business and franchise) to estimate and report GHG emission. Given this revision, the law concerning the rational use of energy constituted after the second oil crisis was revised and has been enacted since April 2010. A company per se (including headquarter, branches, plants with annual energy usage of more than $1500 \mathrm{~m}^{3}$ of crude oil equivalent) needs to report the amount of energy usage to the Government and to be permitted as a designated energy management company. This regulation also targets companies with franchise chain system like Seven-Eleven. The designated company is required to employ a general manager on energy and a project practitioner on energy management. Besides, the revision of the law concerning the promotion of the measures to cope with global warming forces the local authorities, i.e., prefectural and city governments to enact an action plan for suppression of greenhouse gas emission according to natural and local conditions.

In contrast to other local municipalities, the Tokyo Metropolitan Government (TMG) with a population of 130 million and gross regional product of 815 billion USD in 2006 has been independently working on the strategy of "Environmental Revolution" — action toward an environmentally advanced city for a sustainable society. One exemplary action is regulating diesel cars, directly led by Shintaro Ishihara, the governor of TMG.

On Aug 27 1999, the governor Ishihara commenced an active discussion to change the minds of citizens on the use 
of a diesel car. This strategy exhorts citizens: (1) not to ride, purchase, and sell a diesel car: and (2) to accelerate the development of a device and its installation in diesel cars for cleanup of waste gases and particulates. This discussion in which I participated as an advisory board member to TMG resulted in constitution of the Environmental Reservation Treaty. The treaty prohibits a diesel car, which does not fulfill the emission standard of particle matter (PM), to be driven in TMG. A person violating the treaty will be fined 500 thousand yen. Large cities like Osaka and Nagoya also accepted the diesel exhaust emission control measures instituted in Tokyo. Eventually, the top-down decision by Governor Ishihara led to the revision of the national legislation to reduce PM emissions from automobiles in specified areas.

As an action against global warming, TMG asked largescale establishments, which consumes more than $1500 \mathrm{~m}^{3}$ of oil equivalent to report the amount of GHG emission as a voluntary program from the fiscal year 2002 to 2004 (the first step). At the same time, it also asked the regulated parties to create a GHG reduction goal and action plan. In addition, from the fiscal year 2005 to 2009 as the second step, TMG aimed at providing guidance and showcasing good behavior. Nevertheless, the voluntary reduction amounted to a mere $2 \%$, far less than the desired $6 \%$. Hence, it was recognized that the further measures were needed such as:

- allowing no exception to any business from GHG reduction targets

- encouraging top management to recognize the challenges of energy saving and GHG reduction

- creating a management environment where the introduction of the cost on energy saving does not lead to any disadvantage in competition, and

- convincing the regulated parties that climate change cannot be avoided without the reduction of GHG.

Given these points, in addition to the previous spontaneous activities, TMG has performed not only technical discussion with the environmental advisory board but also open-discussion with industries and stakeholders to promote the introduction of the consolidation of $\mathrm{CO}_{2}$ reduction. Expressed opinions against this promotion were: (1) the system governed by bureaucrats inhibits fair competition; (2) it is questionable to maintain fairness; (3) it is less than convincing that restricting the regulatory requirement to large businesses is effective; (4) the increase in the cost for $\mathrm{CO}_{2}$ reduction potentially lowers vital force of Tokyo; and (5) the effectiveness of emission trading system in EU is in question. TMG rebutted these concerns with credible data and insisted on the new system. As a result, the new system was unanimously approved at the Tokyo Metropolitan Congress in 2008.
The system on the obligation of $\mathrm{CO}_{2}$ emission reduction incorporating penalty clauses has been applied since April 2010 (as the third step). This system stems from the obligation of total $\mathrm{CO}_{2}$ emission reduction mainly by a largescale business institution and from the emission trading scheme with cap and trade program.

The amount of $\mathrm{CO}_{2}$ emission in TMG in 2007 was 65 million ton, which was comprised $49 \%$ from commercial and industrial sectors, $27 \%$ from residential sector and $22 \%$ from transportation sector. In the commercial and industrial sectors, a business institution with the total annual energy usage of more than $1500 \mathrm{~m}^{3}$ (large $\mathrm{CO}_{2}$-emitting facilities) and the one with less than $1500 \mathrm{~m}^{3}$ (small to medium sized $\mathrm{CO}_{2}$-emitting facilities) occupy approximately 40 and $60 \%$ of the amount of $\mathrm{CO}_{2}$ emissions, respectively. Hence, a roadmap toward extensive $\mathrm{CO}_{2}$ reduction is promising by enforcing GHG reduction for 1400 large-scale institutions in TMG. They are obliged to reduce the amount of $\mathrm{CO}_{2}$ emission by $8 \%$ from 2010 to 2014 against a reference based on the average amount of $\mathrm{CO}_{2}$ emission from three consecutive years from 2002 to 2007. For example, if a base $\mathrm{CO}_{2}$ emission is 100,000 ton, the total $\mathrm{CO}_{2}$ emission from 2010 to 2014 needs to be lower than 460,000 ton. At this point, the reduction efficiency from 2015 to 2019 is considered to be $17 \%$. In order to accomplish the reduction of $\mathrm{CO}_{2}$ emission, institutions are able to optionally use the emission trading scheme with cap and trade program as the way to reduce $\mathrm{CO}_{2}$ emission through energy saving. The emission trading scheme in TMG will be disclosed at the end of 2010. In this scheme with cap and trade program, if the amount of $\mathrm{CO}_{2}$ reduction exceeds the required amount, the excess reduction can be traded as credit. Moreover, the excess reduction as available credit is exemplified as the amount of $\mathrm{CO}_{2}$ reduction from small and midsize facilities or renewable energy like photovoltaic power generation.

In terms of the amount of $\mathrm{CO}_{2}$ reduction, an independent third-party inspection agency audits and certifies the reduction, or not. If the obliged reduction amount cannot be achieved, the agency orders the business institution to reduce $\mathrm{CO}_{2}$ emission, the amount of which is 1.3 -fold higher than the amount in excess. If a business institution violates the order, it would be fined for less than 500 thousand yen, the name of the institution would be disclosed, and the institution is required to pay money to compensate for the shortage of the $\mathrm{CO}_{2}$ reduction.

Given the final regulatory regime in place now, the construction industry tends to introduce ultra efficient illumination system like LED and state-of-the-art air conditioning system in order to extensively reduce the amount of $\mathrm{CO}_{2}$ emission. Moreover, a building owner provides a tenant with the information on $\mathrm{CO}_{2}$ emission and sets up a consultative meeting on energy saving for the tenant. Installation of LED in a shop and procurement of green 
power by consignment of wind power generation rapidly emerges. Saitama Prefecture, next to TMG, argues for the introduction of emission trading scheme with cap and trade program based on a definitive goal setting. By the way, a special task team in my university was formed this April to the potential of emission trading scheme.

The TMG environmental policy reminds me of the Muskie Act (stringent regulations for exhaust gas emission, e.g., nitrogen oxides, of an automobile proposed by US Senator Muskie in 1970). At that time, the Japanese automobile industry encouraged the development of a lowemission automobile while chanting their opposition to such regulation on nitrogen oxides. As a result, the Honda CVCC engine was successfully developed. Now here comes a question. Is the environmental agenda in TMG, i.e., $8 \%$ of $\mathrm{CO}_{2}$ emission reduction-a big burden-going to retard developments of Japanese enterprises which have been receiving a bitter blow due to declining birth rates and the recent recession? Or, is it going to be a turning point for revitalizing universities and business enterprises by changing tracks or creating new innovative values? Without a doubt, it provides us, i.e., researchers and educators working on environmental issues with a big opportunity to use our talents. 